\title{
Intergenerational transmission of historical memories and social-distance attitudes in post-war second-generation Croatians
}

\author{
Connie Svob ${ }^{1,2}$ • Norman R. Brown ${ }^{1}$ - Vladimir Takšic ${ }^{3}$. \\ Katarina Katulić $^{4}$ • Valnea Žauhar ${ }^{3}$
}

Published online: 29 March 2016

(C) Psychonomic Society, Inc. 2016

\begin{abstract}
Intergenerational transmission of memory is a process by which biographical knowledge contributes to the construction of collective memory (representation of a shared past). We investigated the intergenerational transmission of war-related memories and social-distance attitudes in second-generation post-war Croatians. We compared 2 groups of young adults from (1) Eastern Croatia (extensively affected by the war) and (2) Western Croatia (affected relatively less by the war). Participants were asked to (a) recall the 10 most important events that occurred in one of their parents' lives, (b) estimate the calendar years of each, and (c) provide scale ratings on them. Additionally, (d) all participants completed a modified Bogardus Social Distance scale, as well as an (e) War Events Checklist for their parents' lives. There were several findings. First, approximately two-thirds of Eastern Croatians and one-half of Western Croatians reported warrelated events from their parents' lives. Second, war-related memories impacted the second-generation's identity to a greater extent than did non-war-related memories; this effect was significantly greater in Eastern Croatians than in Western Croatians. Third, war-related events displayed markedly different mnemonic characteristics than non-war-related events. Fourth, the temporal distribution of events surrounding the
\end{abstract}

Connie Svob

consvob@nyspi.columbia.edu

1 Department of Psychology, University of Alberta, Edmonton, Canada

21051 Riverside Drive, Unit 24; Department of Psychiatry, Columbia University Medical Center, New York, NY 10032, USA

3 Department of Psychology, University of Rijeka, Rijeka, Croatia

4 University of Osijek, Osijek, Croatia war produced an upheaval bump, suggesting major transitions (e.g., war) contribute to the way collective memory is formed. And, finally, outright social ostracism and aggression toward out-groups were rarely expressed, independent of region. Nonetheless, social-distance scores were notably higher in Eastern Croatia than in Western Croatia.

Keywords Intergenerational transmission - Collective memory $\cdot$ Transition theory · Autobiographical memory . Xenophobia $\cdot$ Croatian War

Intergenerational transmission is a mechanism by which memory and culture are transmitted. Similar to genetic transmission, it is selective in what is passed on but is unique in that it is socially mediated (Atran, 2001; Coker, 2008; Schönpflug, 2001). Intergenerational transmission has been explored across a wide range of domains, including the transmission of personality traits and psychological disorders in clinical psychology (Kaitz, Levy, Ebstein, Farone, \& Mankuta, 2009; Weingarten, 2004; Yehuda, Bell, Bierer, \& Schmeidler, 2008), the transmission of culture and oral traditions in anthropology (Hoskins, 1998; Kuran, 1998; Sperber, 1994), and the transmission of collective memory and social attitudes in sociology (Halbwachs, 1952/1992; Kraaykamp \& Nieuwbeerta, 2000). Although this interdisciplinary approach has shed light on various aspects of intergenerational transmission, a cohesive theory that bridges individual processes with a collective experience has not been explicated (Hirst \& Manier, 2008; Olick \& Robbins, 1998). We attempt to fill this gap by investigating intergenerational transmission within a socio-cognitive framework. Specifically, we address two main questions: (a) How are the memories of parents who have lived through war remembered by their children, and (b) how do these memories impact social-distance attitudes (i.e., attitudes with preference for some degree of distance from a particular group 
of individuals)? To this end, we compare the intergenerational transmission of memories and social-distance attitudes in secondgeneration Croatians whose parents lived in regions that were either devastated by the war (Eastern Croatia) or were affected relatively little by the war (Western Croatia).

We are at a unique moment in history to accomplish this task. In the early to mid-1990s a devastating war tore Yugoslavia into its constituent, newly independent states. Although the violence has mostly dissipated over the years, interethnic tensions remain in areas where once-warring ethnic groups continue to coexist. This is particularly the case in Croatia, which is composed of Serbian Orthodox, Croatian Catholics, and, to lesser extent, Bosnian Muslims. Intense fear and hatred of respective out-groups may be expected in those who have lived through the horrific experiences of war (Ingelhart, Moaddel, \& Tessler, 2006). However, a generation that has had no direct experience of the war is now emerging into adulthood. It is an opportune time to ask how the war experiences of the first generation will be passed onto the next - what will be remembered, and how will it impact the potential xenophobic attitudes of the next generation?

To answer these questions, we compare two groups of second-generation Croatians - one from Osijek (Eastern Croatia), the other from Rijeka (Western Croatia). Eastern Croatia suffered the greatest degree of devastation from the war as it most nearly borders Serbia (the aggressor against Croatia in the war). The Eastern Croatian river port city, Vukovar, for example, served a critical point in the Croatian war as it was the first Croatian town to fall and surrender to the Serbs (Cigar, 1993). The Eastern region of Croatia suffered an onslaught of bitter fighting for months before the capture of Vukovar's hospital, the massacre of its wounded Croatian prisoners, and the fall of its city in November 1991 (Cigar). At that time, the JNA (Yugoslav People's Army led directly from Serbia) reported that the final surrender comprised 300 Croatian military personnel, 2,000 "unarmed Croatian military, " and 5,000 civilians (Narodna Armija, 1991, as cited in Cigar).

In contrast, Western Croatia was affected relatively little by the war as it is on the opposite side of Croatia along the Adriatic Sea nearly bordering Italy. Furthermore, this region of Istria had top military generals comprising Croatians, Slovenians, and Serbs. As such, the JNA was dissuaded from launching an outright attack on Istria and the northern coastal regions (Cigar, 1993). Instead, the greatest impact of the war in this region comprised a virtual standstill in tourism (the region's top industry), as well as severe suppression in its transport and economic development (Čavlek, 2002; Rivera, 2008).

As a result, the war experiences of people living in Eastern and Western Croatia were markedly different. By comparing groups from the two regions, we are able to determine the degree to which a parent's experience with the war impacts what is remembered by the next generation and the impact it has on its social-distance attitudes.
To this end, we employ a five-phase paradigm. In Phase 1, participants were asked to list the 10 most important events in one of their parents' lives. In Phase 2, the events from Phase 1 were re-presented and the calendar year of each event was estimated. In Phase 3, ratings were collected on the impact each event had on the life and attitudes of both the parent and the participant, respectively. In Phase 4, participants completed a modified Bogardus Social Distance scale (Malešević \& Uzelac, 1997) to provide measures of in-group cohesion and out-group exclusion. And, in Phase 5, participants were asked to respond to an adapted War Events Checklist (Karam, Al-Atrash, Saliba, Melhem, \& Howard, 1999) for their parent's life.

\section{Croatian war and xenophobia}

There were several events that set the stage for the war that was waged in Croatia, including deeply held hatreds percolating from the past millennia to the provocative decision in the mid-1980s to establish a Greater Serbia by claiming Serbian land wherever Serbs had settled (Cigar, 1993). The first palpable and commonly agreed upon trigger of the war, however, began in May 1990 when the first multi-party elections led to the declaration of autonomy from the Serbian-controlled region of Krajina (Cigar; Malešević \& Uzelac, 1997). In June 1991, Croatia declared complete independence and sovereignty from the former Yugoslavia. And, by January 1992, Croatia was internationally recognized as an independent state. Nearly 2 years after the violent turmoil and upheaval began, by the beginning of 1992, approximately one-third of Croatian territory was under the control of local Serb rebels or the JNA. According to Malešević and Uzelac, the character of the defensive war transformed from a military endeavor into one of violent ethnic conflict between Croats, Serbs, and Muslims. Indeed, conduct from the Serbian side suggested a statesanctioned policy to support "ethnic cleansing" (Cigar, 1993, p. 322). These ethnic tensions continued to escalate and, eventually, spread to war in Croatia's neighboring state, Bosnia-Herzegovina, in March, 1992.

At the height of the Croatian and Bosnian wars, Malešević and Uzelac (1997) surveyed young adults' social attitudes in Zagreb, the capital city of Croatia (in May 1992 and June 1993). Approximately $80 \%$ of the respondents were not impacted by the war directly (e.g., exposed to heavy shelling or bombing), yet the growing impact of the war on their xenophobic attitudes was evident with social-distance scores being significantly higher in 1993 than in 1992. To examine the degree to which these attitudes proliferate across generations, we employed the same modified Bogardus Social Distance scale with the subsequent generation of Croatians. At the time of data collection, this second generation was approximately 
the same age as the parent's generation in Malešević and Uzelac's study.

The Bogardus Social Distance scale (Bogardus, 1928) measures the willingness of people to engage in social contact with various groups. The scale does not measure the degree of hostility per se, but rather implies an omnibus measure of hatred, hostility, disgust, and fear. Malešević and Uzelac (1997) expanded the standard Bogardus Social Distance scale from seven to nine degrees of social acceptance. The scale comprised a continuum of three parts: (a) ethnic cohesion, (b) ethnic ostracism, and (c) ethnic aggression. Taken together, the latter two sections suggest out-group exclusion, while the former implies in-group solidarity. Nine degrees of acceptance were offered for 11 ethnic groups, ranging from "close relatives by marriage" to "I would personally exterminate all of them." Higher group mean differences suggested greater social distance. The greatest social distance reported by Croatians was toward Serbs in 1992 and 1993. Furthermore, there was a startling increase in social-distance attitudes toward Muslims between 1992 and 1993.

\section{Collective memory, transitions, and identity}

We situate the present study within the context of collective memory. Collective memory can be defined as a representation of a past that is shared by members of a common social group (Zaromb, Butler, Agarwal, \& Roediger, 2014). Collective memory studies generally focus on public historical events that impact a fairly large group of people. Collective memory studies can, however, also include smaller groups of individuals, such as couples (Harris, Keil, Sutton, Barnier, \& McIlwain, 2011) and families (Fiese, Hooker, Kotary, Schwagler, \& Rimmer, 1995; Fivush, Bohanek, \& Duke, 2008) recollecting various significant events (Halbwachs, 1952/1980). In the present study we examine the transmission of important life events from a parent's life. In particular, we are interested in the transmission of historical events, the way they are organized in memory, and their impact on socialdistance attitudes.

\section{Transition theory}

One theory of memory, transition theory (Brown, Hansen, Lee, Vanderveen, \& Conrad, 2012; Brown \& Lee, 2010; Brown et al., 2009; Brown, Schweickart, \& Svob, 2016; Nourkova \& Brown, 2014; Zebian \& Brown, 2014), has investigated the impact of historical events on memory. According to transition theory, memory is organized by events that signal or cause marked changes in the ordinary circumstances of daily life; such events are called transitions. As such, a life transition can be operationalized as an event that produces high degrees of material and psychological change (Svob, Brown, Reddon, Uzer, \& Lee, 2014). In particular,
Brown and colleagues have examined the impact of public, historical events on autobiographical memory and have observed a Living-in-History (LiH) effect (Brown et al., 2009). That is, personal events were dated frequently with respect to public historical events in populations that had undergone sudden, unexpected, dramatic, and prolonged disruptions to the fabric of their daily lives (e.g., Bosnians who lived through the Siege of Sarajevo; residents of Ismit, Turkey, who survived a catastrophic earthquake in 1991).

Transition theory has also been supported in memory across generations. Svob and Brown (2012) asked adult children of parents who emigrated due to violent political upheaval to list the 10 most important events in their parents' lives and to estimate the date of each while talking aloud. The $\mathrm{LiH}$ effect was also observed in the mnemonic distribution of a parent's life in $5 \%$ of dating protocols (compared to approximately $23 \%$ in Brown et al.'s studies). The temporal distribution of a parent's life was structured according to major life transitions - in particular, immigration, producing an immigration bump. Moreover, $25 \%$ of the events reported from a parent's life were historical.

In a follow-up study by Svob (2014), adult children of voluntary immigrants, refugees, and life-long Canadians demonstrated a similar pattern of findings. Notably, an immigration bump was observed in the temporal distribution of a parent's life for both the immigrant and refugee groups, respectively. Furthermore, $24 \%$ of the events reported from the refugee parents' lives and $10 \%$ of the events from the immigrant parents' lives were historically relevant.

The present study builds upon and extends the work of Svob and Brown (2012) and Svob (2014). We examine the transmitted events and attitudes of a generation whose parents lived through a terrible war but, unlike the participants' parents in the previous studies, did not immigrate. As such, an immigration bump will not be present in the temporal distribution of a parent's life. Alternatively, in accordance with transition theory, an upheaval bump (Brown et al., 2016) for the years of the war was expected. By keeping both the political conflict and ethnic groups constant, we were able to examine potential xenophobic attitudes across geographical regions. Moreover, the Croatian participants provide an age-matched sample for comparison to Svob and Brown's participants.

\section{Memory and identity}

Another important component of memory is identity. The relation between identity and what is remembered has provided the basis for various models of autobiographical memory and may well extend to the intergenerational transmission of collective memory, as well. For example, Conway's (2005) selfmemory system model of autobiographical memory asserts that the role and function of autobiographical memory is to define the self and, in turn, the self regulates and constrains 
what is remembered. It has also been shown that there is a strong association between identity and historical memory. Historical memories are often tilted in favor of one's ingroup and are thereby skewed, selective, and biased in their depictions of the past (Blatz \& Ross, 2009; Sahdra \& Ross, 2007; Welzer, 2005; Wohl \& Branscombe, 2009). Moreover, when a multigenerational association is established between a group and an individual - or, put another way, when group identity is adopted as personal identity - it may help form what Fivush et al. (2008) refer to as an intergenerational self. Importantly, however, other work on historical memories has shown that memories are often localized to the generation/ cohort that lived through them (Holmes \& Conway, 1999; Mannheim, 1952), become less personally relevant across time (Schuman \& Scott, 1989), and fade across generations (Stone, van der Haegen, Luminet, \& Hirst, 2014), suggesting identity may not be the driving force behind the transmission of collective memory, after all.

\section{Predictions of present study}

In this exploratory empirical study, we seek to better understand the individual processes involved in the construction of history and their correlations with social-distance attitudes. Specifically, we aim to provide data on whether knowledge of, or the explicit sharing of, war experiences fuels or mitigates hateful attitudes in subsequent generations, as well as provide insight into the ways personal memory transforms into historical memory.

First, we expect a greater amount of historical conflictknowledge to be transmitted through the life stories of parents from the extensively war-torn region of Eastern Croatia than from the comparatively less impacted region of Western Croatia. The degree to which event narratives are explicitly shared with the second-generation (rehearsal) may, however, impact not only what is subsequently remembered but also the degree to which xenophobic attitudes proliferate. For instance, it has been shown that silence surrounding the experiences of Holocaust survivors is a predictor of trauma in the second generation (Anacharoff, Munroe, \& Fisher, 1998). The intentional silencing, or discussion, of a parent's war experiences may be further predictive of what events are considered most important in a parent's life, as well as the degree to which social-distance attitudes prevail.

Second, given the passage of time and lack of direct impact by the war, we expect the social-distance attitudes of the postwar generation to be mitigated in comparison to the xenophobic attitudes reported by the generation that was directly and immediately impacted by the Croatian war (Malešević \& Uzelac, 1997). Alternatively, if the second generation absorbs the burden of reversing what was done to the first (Volkan, 1997), more extreme degrees of social-distance attitudes may be observed in the second generation than in the first generation.

Third, we suspect that the social-distance attitudes reported will be greater in Eastern Croatia than in Western Croatia. Although the expression of social-distance attitudes is socially mediated and culturally sanctioned, we expect that a parent's individual experience will override attitudes related solely to group identity (i.e., being a Croatian). As such, social-distance attitudes toward Serbs should be greater in Eastern Croatia than in Western Croatia, whereas social-distance scores towards nonperpetrators (e.g., Italians) should be comparable across the two regions.

Finally, in relation to transition theory, we expect the major transitions wrought by the civil war to demonstrate an upheaval bump in the temporal distribution of events reported by both groups. The group from Eastern Croatia, however, will likely exhibit a more robust bump than the group from Western Croatia due to the greater impact the war had on the residents of Eastern Croatia (Svob et al., 2014).

\section{Method}

\section{Participants}

A total of 96 people participated in the study, 36 at the University of Osijek in Eastern Croatia (32 females, 4 males; ages $18-21$ years, $M=19.3, S D=0.64)$ and 60 at the University of Rijeka in Western Croatia (47 females, 13 males; ages $18-20$ years, $M=19.2, S D=0.48$ ). Both groups of participants were recruited through introductory psychology classes and received course credit. Four additional participants in Western Croatia were excluded from the study prior to analysis because they failed to report 10 events from their parent's life and, as such, were unable to provide date estimates and ratings for the events. Also, one additional participant was excluded from analysis from Eastern Croatia as she self-identified as a Serbian, which would contaminate the data, as we are interested in, specifically, the attitudes of Croatians in Croatia in the present study. All of the participants' parents had remained in their respective regions following the war (i.e., there was no cross-migration).

\section{Materials}

The materials used for Phases 1 through 3 of the experiment were self-generated and data driven. As discussed below, participants in the first three phases reported important events from their parents' lives to which they further provided date estimates and ratings. In Phase 4, we administered a modified Bogardus Social Distance scale (Malešević \& Uzelac, 1997). And, in Phase 5, participants responded to a modified War Events checklist (Karam et al., 1999). 
Bogardus social distance scale The Bogardus Social Distance scale (Bogardus, 1928) is a self-report assessment tool that measures the degree to which people are willing to engage in contact with other groups. Respondents state reactions to statements varying in intensity of closeness. Following the modified Bogardus Social Distance scale used by Malešević and Uzelac (1997), participants in the present study were instructed as follows: Based on your first feeling reaction, please indicate how you feel about having members of the following groups as: Close relatives by marriage; Close personal friends; Colleagues at work; Citizens in my town; Citizens in my country; Avoid all contact with them; Forbid them entry to my country; Would like someone to kill them all; Would personally exterminate them all. The ratings for the various ethnic groups included Albanians, Croatians, Italians, Germans, Hungarians, Macedonians, Montenegrins, Muslims, Russians, Serbians, and Slovenians. Higher differences between group means equate with greater social distance, a lower willingness to assume contact, and a stronger negative prejudice toward other groups.

War events checklist Participants were asked to complete a 10-item War Events Checklist. The events were adapted from the major categories of Karam et al.'s (1999) War Events Questionnaire. Our respondents indicated Yes, No, or Unsure to the following 10 questions regarding their parents' experiences in the Croatian war: Did your parent experience any form of displacement (e.g., forced to change home, school, etc.) during the war; Did your parent emigrate (leave Croatia) because of the war; Did your parent experience separation from their loved ones during the war; Did your parent experience bereavement (death of a loved one) because of the war; Did your parent witness any violent acts (e.g., intimidation, torture, killing) during the war; Was your parent exposed to shelling, bombing, or combat during the war; Was your parent a victim of any violent act(s) during the war; Did your parent suffer any physical injuries during the war; Was your parent involved in the hostilities (e.g., fought in the army, carried weapons, etc.) of the war; Did your parent experience extreme deprivation (e.g., of food, water, shelter) during the war? The War Events Checklist was used primarily as a validity measure to ensure the two groups indeed varied by region in the degree to which they suffered the atrocities wrought by the war.

\section{Procedure}

The experiment was delivered on individual computers within a computer lab. It was self-paced and required approximately 30 to 45 minutes to complete. The materials were all presented in Croatian after being back-translated from English by four research assistants that were fluent in both English and
Croatian. After providing informed consent, the experiment comprised five phases.

In Phase 1, participants were asked to choose a parent and to list the 10 most important events from that parent's life. The events could be from any period, from the time their parent was born up to the present and did not have to be listed in any particular order. There were only two restrictions: (a) to restrict the birth of children to one event (if chosen as part of the list), unless there was something distinct about the birth of a child, and (b) to exclude the parent's birth as one of the important events.

In Phase 2, the events reported in Phase 1 were re-presented one at a time and in random order. Participants were asked to provide an estimate of the calendar year when each event occurred. They could choose a year from a menu of years spanning 1930 to 2013.

Phase 3 was divided into two sections and replicated the rating scales used by Svob (2014). In Phase 3a, participants rated (on a 5-point scale) the degree to which they perceived each event to have impacted their parent's life. The items included the belief that the event changed their parent's external material circumstances $(1=$ completely disagree; $5=$ completely agree), that the event impacted their parent psychologically $(1=$ completely disagree; $5=$ completely agree $)$, the degree to which the parent talked about each event with the participant $(1=$ never $; 5=$ frequently $)$, and the valence of each event $(1=$ extremely negative; $5=$ extremely positive $)$. Finally, the participant rated the degree to which each event was related to the Croatian war $(1=$ not at all; $5=$ completely $)$.

In Phase $3 \mathrm{~b}$, participants again provided ratings on the events reported in Phase 1, but this time they were asked to report the degree of impact each event had on their own life instead of their parent's. On a 5-point scale, participants rated the degree to which they agreed $(1=$ completely disagree; $5=$ completely agree) that each event impacted their own sense of identity, impacts their life decisions, helps them to better understand their parent, and influences their relationships with others.

Phase 4 required responses to the modified Bogardus Social Distance scale (Malešević \& Uzelac, 1997). And, in Phase 5, participants completed the War Events Checklist. Once the study was completed, participants were debriefed.

\section{Results and discussion}

The following section is divided into three subsections to address the issues raised in the introduction. First, we compare the two groups (Eastern and Western Croatians) on the War Experiences Checklist and the degree to which historical conflict was transmitted via a parent's life story. Next, we characterize the memories of the events from a parent's life and compare their temporal distribution across regions and event 
types. Finally, we examine the Bogardus social-distance scores for 11 ethnic groups and compare these scores by region and generation (parent's generation vs. present generation), respectively.

\section{Historical conflict knowledge}

The Eastern and Western samples were similar in several respects. As previously noted, the participants were similar in age and were predominantly female. Furthermore, almost two-thirds of all the events reported were from a mother's life rather than a father's (Eastern Croatia, $58.3 \%$; Western Croatia, $61.7 \%$ ). Aside from location, the only demographical difference between the two regions was that the average age of the parent was modestly higher in Eastern Croatia $(M=$ 50.4 years, $S D=6.37)$ than in Western Croatia $(M=$ 48.9 years, $S D=5.62) ; t(95)=3.96, p<.001, d=0.81$, $95 \%$ CI $[0.79,2.34]$.

As predicted, the war experiences of Eastern Croatians were more extensive than they were for Western Croatians. On the War Events Checklist, Eastern Croatians reported an average between 4.00 and 5.53 (out of 10) events experienced by their parent during the war, whereas Western Croatians reported an average of 2.40 to 3.88 . The lower end of the range refers to the average number of times "Yes" was indicated to indicate a war-related event was experienced, whereas the upper range includes the average number of "Unsure" responses. To be conservative, we considered only the "Yes" responses for the purposes of our statistical comparison and found a significant difference between groups, $t(94)=3.72, p$ $<.001, d=0.77,95 \% \mathrm{CI}[0.75,2.45]$. That is, the parents' war experiences in Eastern Croatia were significantly greater than they were in Western Croatians. This confirms that the groups indeed differed in the extent to which they were affected by the war and supports our presumption that the two regions of Croatia were variably affected by the war.

Measures of historical conflict-knowledge from a parent's war experience were derived from the scale item regarding each reported event's relation to the war. Responses of 4 or 5 (on a 5-point scale) constituted a war-related event, whereas responses of 3 or lower were considered non-war related. As predicted, historical conflict knowledge was transmitted via a parent's life story in both Eastern and Western postwar Croatians, with a greater percentage of participants reporting war-related events in Eastern Croatia than in Western Croatia. In Eastern Croatia, approximately two-thirds (66.7 \%) of participants reported at least one war-related event from a parent's life, whereas only about a half $(51.7 \%)$ of the subjects reported war-related events in Western Croatia. This suggests that war-related memories are transmitted across generations in accordance with the impact of the war experiences themselves.

\section{Memory for events from parent's life}

Next, we consider the memory-related ratings of identity, rehearsal, valence, material change, and psychological change, life decisions, understanding one's parent, and relationships with others (see Table 1). All of these factors have been implicated as core features of autobiographical memory. Planned pairwise comparisons revealed that the two groups were comparable on all measures (all $p \mathrm{~s}>.05$ ), with the exception of identity. That is Eastern Croatians identified with their parent's life stories to a greater extent than Western Croatians, $t(94)=$ $2.01, p=.048, d=0.42,95 \%$ CI [0.002, 0.57]. Consistent with general findings in autobiographical memory research, the recalled events from a parent's life were on average rehearsed fairly frequently, were fairly positive, and were perceived to cause material and psychological changes to their parent's lives (i.e., they were transitional in nature).

Another way to look at the characteristics of transmitted historical memories is to compare the properties of war-related events versus non-war-related events (see Table 2). We explored mnemonic characteristics between geographical regions (Eastern Croatia vs. Western Croatia) and between particular event types (war-related events vs. non-war-related events). We ran a $2 \times 2$ mixed ANOVA and found a main effect of war-related events on all mnemonic measures. No significant effect of region was observed, nor any interaction between event type and geographical region (all $p \mathrm{~s}>.05$ ). Specifically, in comparison to non-warrelated events, war-related events (a) impacted the second generation's identity, $F(1,952)=17.04, M S E=38.88, p<.001, \eta_{\mathrm{p}}{ }^{2}=$ .02 ; (b) were rehearsed (marginally) more frequently, $F(1,855)=$ 3.72, MSE $=4.89, p=.05, \eta_{\mathrm{p}}{ }^{2}=.004$; (c) were less positive, $F(1$, $954)=22.03, M S E=47.66, p<.001, \eta_{\mathrm{p}}^{2}=.02 ;$ (d) produced more material change in the parent's life, $F(1,950)=23.67, M S E$ $=33.27, p<.001, \eta_{\mathrm{p}}^{2}=.02 ;$ (e) produced greater psychological change in the parent, $F(1,955)=14.98, M S E=17.95, p<.001$, $\eta_{\mathrm{p}}{ }^{2}=.02$; (f) impacted the second-generation's life decisions, $F(1,952)=6.17, M S E=12.55, p=.01, \eta_{\mathrm{p}}{ }^{2}=.006 ;(\mathrm{g})$ helped the second generation to better understand their parent, $F(1,952)$

Table 1 Mean (Standard Error) Ratings (5-point scale) of Important Parental Memories in Eastern and Western Croatia

\begin{tabular}{lll}
\hline & Eastern & Western \\
\hline Identity & $3.04(0.03)^{*}$ & $2.75(0.03)$ \\
Rehearsal & $3.55(0.07)$ & $3.62(0.05)$ \\
Valence & $3.73(0.08)$ & $3.79(0.06)$ \\
Material Change & $3.77(0.06)$ & $3.78(0.05)$ \\
Psychological Change & $3.69(0.06)$ & $3.71(0.05)$ \\
Life Decisions & $2.54(0.07)$ & $2.41(0.06)$ \\
Understand Parent & $3.42(0.07)$ & $3.19(0.06)$ \\
Other Relationships & $2.38(0.08)$ & $2.17(0.06)$ \\
\hline
\end{tabular}

$* p=.048$ 
Table 2 Mean (Standard Error) Ratings (5-point scale) of War-Related and Non-War-Related Memories in Eastern and Western Croatia

\begin{tabular}{llll}
\hline & & $\begin{array}{l}\text { War-Related } \\
\text { Memories }\end{array}$ & $\begin{array}{l}\text { Non-War-Related } \\
\text { Memories }\end{array}$ \\
\hline Identity* & East & $3.48(0.17)$ & $2.96(0.08)$ \\
& West & $3.43(0.18)$ & $2.67(0.07)$ \\
Rehearsal* & East & $3.90(0.19)$ & $3.49(0.07)$ \\
& West & $3.68(0.14)$ & $3.61(0.05)$ \\
Valence* & East & $3.30(0.26)$ & $3.80(0.09)$ \\
Material Change* & West & $2.97(0.22)$ & $3.88(0.06)$ \\
& East & $4.30(0.12)$ & $3.68(0.07)$ \\
Psychological Change* & West & $4.28(0.14)$ & $3.72(0.05)$ \\
& East & $4.02(0.13)$ & $3.64(0.06)$ \\
Life Decisions* & West & $4.15(0.13)$ & $3.66(0.05)$ \\
& East & $2.78(0.21)$ & $2.51(0.08)$ \\
Understand Parent* & West & $2.82(0.18)$ & $2.37(0.06)$ \\
& East & $3.88(0.17)$ & $3.34(0.08)$ \\
Other Relationships* & West & $3.72(0.18)$ & $3.13(0.06)$ \\
& East & $2.84(0.20)$ & $2.30(0.08)$ \\
& West & $2.95(0.18)$ & $2.09(0.06)$ \\
\hline
\end{tabular}

*Main effect of war-related memories, $p \leq .05$

$=17.09, M S E=30.48, p<.001, \eta_{\mathrm{p}}{ }^{2}=.02 ;$ and $(\mathrm{h})$ influenced the second generation's relationships with others, $F(1,947)=25.26$, $M S E=47.21, p<.001, \eta_{\mathrm{p}}^{2}=.03$. Taken together, these results suggest that war-related events constitute a unique event type in memory and contain domain-specific mnemonic characteristics that are independent of geographical region.

We note that war-related events were rehearsed marginally more than non-war-related events. This suggests that the potential silencing of war memories is not contributing significantly to the way these events are being transmitted in memory. Of course, this is only speculative, as our data do not allow us to access the veridicality, accuracy, or details of the events that were transmitted. Nonetheless, for the most part, our data suggest that in comparison to other events from a parent's life story, war stories are shared and transmitted to a similar degree.

Furthermore, we note that as predicted, the transitional ratings (of material and psychological change) were high. Accordingly, transition theory predicted that the distribution of events surrounding the war would create an upheaval bump (Brown et al., 2016). Indeed, this was observed for both Eastern and Western Croatians (see Fig. 1). Despite Western Croatians demonstrating a modestly mitigated effect, pairwise comparisons using the Kolmogorov-Smirnov test revealed that the distributions between the two groups were comparable $(p=.89)$. This suggests the pattern of results was the same and that both groups exhibit an upheaval bump. This finding supports the notion that major life transitions structure both personal and collective memory.

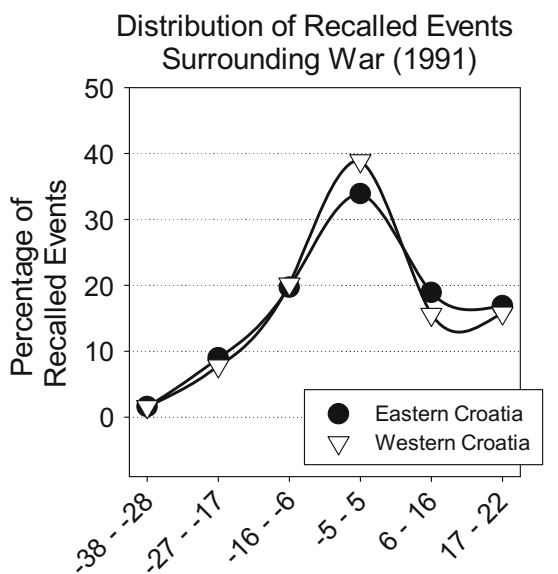

Estimated Date Relative to the War

Fig. 1 Upheaval bump - temporal distribution of events surrounding Croatian War (1991)

It should be noted that the upheaval bump is conflated with the formative years typically associated with the reminiscence bump (15-30 years). In our sample, the average age of parents in Eastern Croatia at the time of the war was 28.8 years, and 27.1 years in Western Croatia. War-related events were not as evenly distributed across the lifespan as were non-war-related events (see Fig. 2), suggesting that war-related events indeed impact the robustness of the upheaval bump. Hence, we may surmise that the single event of war serves as a central structural marker in the temporal distribution of a Croatian parent's life events, just as immigration did for the lives of refugee parents in Svob and Brown's (2012) study. In addition to transitions, it is also possible that other factors may be contributing to the observed bump-for example, identity formation associated with living through war, the conceptual importance of a historical event, and emotional charge and intensity.

\section{Social-distance attitudes}

In this final section, we examine the social-distance attitudes of second-generation postwar Croatians. Social-distance

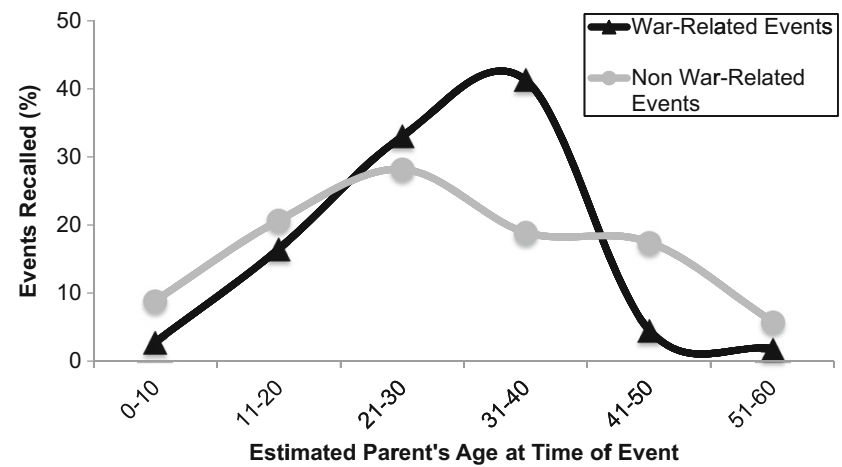

Fig. 2 Distribution of events children recalled from one of their parents' lives as a function of the parent's estimated age at the time of the event and event type 
Table 3 Mean (Standard Error) Scores and Rankings on Modified Bogardus Social Distance Scale

\begin{tabular}{|c|c|c|c|c|c|c|}
\hline & Eastern Croatia (2013) & Rank & Western Croatia (2013) & Rank & Central Croatia $(1993)^{\wedge}$ & Rank \\
\hline Muslims* & $3.14(0.29)$ & 1 & $2.23(0.23)$ & 2 & 4.17 & 4 \\
\hline Albanians & $2.94(0.30)$ & 2 & $2.80(0.27)$ & 1 & 4.43 & 3 \\
\hline Serbians* & $2.89(0.25)$ & 3 & $2.23(0.25)$ & 4 & 4.73 & 1 \\
\hline Slovenians* & $2.81(0.29)$ & 4 & $2.02(0.21)$ & 8 & 3.63 & 6 \\
\hline Montenegrins & $2.69(0.32)$ & 5 & $2.05(0.23)$ & 6 & 4.51 & 2 \\
\hline Russians* & $2.69(0.31)$ & 6 & $1.87(0.23)$ & 10 & 3.91 & 5 \\
\hline Macedonians & $2.61(0.32)$ & 7 & $2.10(0.23)$ & 5 & 3.50 & 7 \\
\hline Hungarians & $2.64(0.29)$ & 8 & $2.05(0.24)$ & 7 & 3.04 & 9 \\
\hline Germans & $2.19(0.29)$ & 9 & $2.13(0.21)$ & 3 & 2.79 & 10 \\
\hline Italians & $2.42(0.32)$ & 10 & $1.85(0.19)$ & 9 & 3.08 & 8 \\
\hline Croatians & $1.03(0.03)$ & 11 & $1.15(0.08)$ & 11 & 1.33 & 11 \\
\hline
\end{tabular}

^ Modified Bogardus Social Distance scale means reported in Malešević and Uzelac (1997) in 1993; *Statistically significant difference between Eastern and Western Croatia (2013), $p<.05$

scores (group means across various ethnic groups ${ }^{1}$ ) on the modified Bogardus Social Distance scale were similar across Eastern and Western Croatians in both rank and degree (see Table 3). Planned pairwise comparisons revealed expected differences between the two regions with greater social distance expressed in Eastern Croatia for groups that were implicated in war hostilities against Croatians, namely, Serbians and Bosnian Muslims.

The overall pattern of responses by second-generation Croatians was similar, yet mitigated, in comparison to the parent's generation (Malešević \& Uzelac, 1997). Attitudes in the East most strongly resembled those of the parent's generation (see Table 4) but were less extreme. Although, extreme hatred and aggression were rarely reported by secondgeneration Croatians, it is interesting to note that the few groups toward whom these attitudes were expressed corresponded to the same groups toward whom they were expressed in their parent's generation. This suggests that some of these social-distance attitudes are, nonetheless, being transmitted across generations, however, to a much lesser extent than one might have expected.

It should also be noted that it is difficult to compare results of the Bogardus Social Distance scale across generations as the scale may pick up acceptance and rejection ratings in a drastically different way during times of intense conflict than it does twenty years postconflict. Furthermore, socially desirable responding may bias the measures we are comparing. During times of war, hatred for the "enemy" is often encouraged socially, whereas 20 years later expressed hostility may be discouraged in order to promote peace. Implicit measures

\footnotetext{
${ }^{1}$ To obtain average scores one must assume a scale has interval properties. It is, however, implausible that the Likert scales in the modified Bogardus Social Distance scale have equal intervals between adjacent scale points. Nonetheless, for comparative purposes with Malešević and Uzelac's (1997) study, we have chosen to report them.
}

of social attitudes (e.g., the implicit association test; Greenwald, McGhee, \& Schwartz, 1998) would be helpful to provide additional insight into these findings and to circumvent potential biases in self-report measures. This is something that is left to future research.

\section{General discussion}

In this paper we examined the intergenerational transmission of historical conflict via a parent's life story as well as the intergenerational transmission of social-distance attitudes toward in-groups and out-groups. We collected data from second-generation postwar Croatians living in two separate regions, one more extensively affected by the war than the other (i.e., Eastern and Western Croatia, respectively). There were several findings. First, as expected, more people in Eastern Croatia than in Western Croatia reported war-related events from a parent's life. Second, war-related memories affected the second generation's identity to a greater extent than did non-war-related memories; this effect was significantly greater in Eastern Croatians than in Western Croatians. Third, the mnemonic characteristics of historical events were distinct from those of non-war-related events. Fourth, the Croatian war created an upheaval bump in the temporal

Table 4 Pearson Correlations for Social-Distance Attitudes Between Croatian Generations and Regions

\begin{tabular}{llll}
\hline & Eastern (2013) & Western (2013) & Central (1993) \\
\hline Eastern (2013) & 1.00 & & \\
Western (2013) & $.82 *$ & 1.00 & \\
Central (1993) & $.90 *$ & $.77 *$ & 1.00 \\
\hline$* p<.01$ & & &
\end{tabular}


distribution of important events from a parent's life. Fifth, social-distance scores for groups implicated in wartime aggression were significantly higher in Eastern than in Western Croatia. Finally, xenophobic attitudes observed in the parent's generation in 1993 (Malešević \& Uzelac, 1997) were greatly diminished in the postwar generation 20 years later.

The importance of placing one's own life within the context of an ethnic heritage and family history has been emphasized by the present study. Doing so provides a framework for understanding oneself as a member of a group that extends before one's birth and provides the context and direction for an individual's life story to unfold (Fivush, 2008). Accordingly, a person's life may be embedded within the life stories of people that are both past and present. Granted, the stories passed on from one generation to the next, especially those that concern daily life in war, may be regarded as sequences of fragmented, separate tellings of particular anecdotes. For members belonging to the same group, however, such segmented stories appear to seek a common theme and yield a larger unity that transcends explicit textualization (Povrzanović, 2000). As such, these stories become the bedrock upon which group identity, collective memory, and history are formed.

According to Assmann (1995), collective memory preserves the store of its knowledge precisely through the awareness of a group's unity and peculiarity. The content of historical knowledge is uniquely characterized by the sharp distinctions made between those who belong and those who do not. One's relation to the group drives what is remembered and how it is transmitted and acquired by subsequent generations. To a certain extent, our data support this notion and underline the importance of identity in the intergenerational transmission of collective memory. War-related events in particular may be more important and emotionally salient than more scripted and expected events. As such, war-related memories from a parent's life may impact the subsequent generation's sense of self and, by extension, an accumulation of warrelated memories in society may result in the formation of intergenerational identity for the collective. In contrast to Assmann, our findings suggest that this process develops much earlier - that is, it begins to unfold between Generation 0 and Generation 1 (within 20 years), instead of, as Assmann suggests, between 80 to 100 years later.

To end, one of the most intriguing results of the present study was that, for the most part, explicit ostracism and aggression toward ethnic out-groups was not expressed. There may be several reasons for this, including our predominantly female, university-educated sample, as well as social pressures to conceal provocative and potentially inciting attitudes. Despite the fact that our samples were of convenience and were not representative, and that there may have been a tendency for subjects to provide socially desirable responses, it remains an important finding. That is, it suggests memory for a parent's war-related experiences can be dissociated from the potentially hateful attitudes they originally engendered. Remembering in this case, may serve a learning function for subsequent generations. Collective memory may, therefore, serve not only to perpetuate intergroup hostilities (Ingelhart et al., 2006) but to promote intergroup acceptance, tolerance, and peace.

Author Note This research was supported in part by a Government of Canada-Social Sciences and Humanities Research Council of Canada (SSHRC) doctoral scholarship and SSHRC-CGS Michael Smith Foreign Study Supplement awarded to the first author and a SSHRC Insight Grant awarded to the second author.

\section{References}

Anacharoff, M. R., Munroe, J. F., \& Fisher, L. M. (1998). The legacy of combat trauma: Clinical implications of intergenerational transmission. In Y. Danieli (Ed.), International handbook of multigenerational legacies of trauma (pp. 257-276). New York, NY: Plenum Press.

Assmann, J. (1995). Collective memory and cultural identity. New German Critique, 65, 125-133. doi:10.2307/488538

Atran, S. (2001). The trouble with memes: Inference versus imitation in cultural creation. Human Nature, 12, 351-381. doi:10.1007/s12110001-1003-0

Blatz, C. W., \& Ross, M. (2009). Historical memories. In P. Boyer \& J. V. Wertsch (Eds.), Memory in mind and culture (pp. 223-237). Cambridge, UK: Cambridge Press.

Bogardus, E. S. (1928). Immigration and race attitudes. Boston, MA: Heath.

Brown, N. R., Hansen, G. B., Lee, P. J., Vanderveen, S. A., \& Conrad, F. G. (2012). Historically defined autobiographical periods: Their origins and implications. In D. Berntsen (Ed.), Theoretical perspectives on autobiographical memory (pp. 160-180). Cambridge, UK: Cambridge University Press.

Brown, N. R., \& Lee, P. J. (2010). Public events and the organization of autobiographical memory: An overview of the Living-in-History Project. Behavioral Sciences of Terrorism and Political Aggression, 2, 133-149. doi:10.1080/19434471003597431

Brown, N. R., Lee, P. J., Krslak, M., Conrad, F. G., Hansen, T., Havelka, J., \& Reddon, J. R. (2009). Living in history: How war, terrorism, and natural disaster affect the organization of autobiographical memory. Psychological Science, 20, 399-405. doi:10.1111/j.14679280.2009.02307.x

Brown, N. R., Schweickart, O., \& Svob, C. (2016). The effect of collective transitions on the organization and contents of autobiographical memory: A transition-theory perspective. Journal of American Psychology. In press

Čavlek, N. (2002). Tour operators and destination safety. Annals of Tourism Research, 29, 478-496. doi:10.1016/S0160-7383(01) 00067-6

Cigar, N. (1993). The SerboCroatian war, 1991: Political and military dimensions. Journal of Strategic Studies, 16, 297-338. doi:10. 1080/01402399308437521

Coker, C. (2008). War, memes, and memeplexes. International Affairs, 84, 903-914. doi:10.1111/j.1468-2346.2008.00745.x

Conway, M. A. (2005). Memory and the self. Journal of Memory and Language, 53, 594-628. doi:10.1016/j.jml.2005.08.005

Fiese, B. H., Hooker, K. A., Kotary, L., Schwagler, J., \& Rimmer, M. (1995). Family stories in the early stages of parenthood. Journal of Marriage and the Family, 763-770. doi:10.2307/353930 
Fivush, R. (2008). Remembering and reminiscing: How individual lives are constructed in family narratives. Memory Studies, 1, 49-58. doi: $10.1177 / 1750698007083888$

Fivush, R., Bohanek, J. G., \& Duke, M. P. (2008). The intergenerational self: Subjective perspective and family history. In F. Sani (Ed.), Individual and collective self-continuity (pp. 131-143). Mahwah, NJ: Erlbaum.

Greenwald, A. G., McGhee, D. E., \& Schwartz, J. L. K. (1998). Measuring individual differences in implicit cognition: The implicit association test. Journal of Personality and Social Psychology, 74, 1464-1480. doi:10.1037/0022-3514.74.6.1464

Halbwachs, M. (1952/1992). On collective memory (L. A. Coser, Trans.). Chicago, IL: University of Chicago Press. (Original work published 1952)

Harris, C. B., Keil, P. G., Sutton, J., Barnier, A. J., \& McIlwain, D. J. (2011). We remember, we forget: Collaborative remembering in older couples. Discourse Processes, 48, 267-303. doi:10.1080/ 0163853X.2010.541854

Hirst, W., \& Manier, D. (2008). Towards a psychology of collective memory. Memory, 16, 183-200. doi:10.1080/09658210701811912

Holmes, A., \& Conway, M. A. (1999). Generation identity and the reminiscence bump: Memory for public and private events. Journal of Adult Development, 6, 21-34. doi:10.1023/A:1021620224085

Hoskins, J. (1998). Biographical objects: How things tell the stories of people's lives. New York, NY: Routledge.

Ingelhart, R., Moaddel, M., \& Tessler, M. (2006). Xenophobia and ingroup solidarity in Iraq: A natural experiment on the impact of insecurity. Perspectives on Politics, 4, 495-505. doi:10.1017/ S1537592706060324

Kaitz, M., Levy, M., Ebstein, R., Farone, S. V., \& Mankuta, D. (2009). The intergenerational effects of trauma from terror: A real possibility. Infant Mental Health Journal, 30, 158-179. doi:10.1002/imhj. 20209

Karam, E., Al-Atrash, R., Saliba, S., Melhem, N., \& Howard, D. (1999). The war events questionnaire. Social Psychiatry Psychiatric Epidemiology, 34, 265-274. doi:10.1016/j.jad.2008.03.016

Kraaykamp, G., \& Nieuwbeerta, P. (2000). Parental background and lifestyle differentiation in Eastern Europe: Social, political, and cultural intergenerational transmission in five former socialist societies. Social Science Research, 29, 92-122. doi: 10.1006/ssre.1999.0655

Kuran, T. (1998). Ethnic norms and their transformation through reputational cascades. Journal of Legal Studies, 27, 623-659. doi:10.1086/ 468038

Malešević, S., \& Uzelac, G. (1997). Ethnic distance, power and war: The case of Croatian students. Nations and Nationalism, 3, 291-298. doi:10.1111/j.1354-5078.1997.00291.x

Mannheim, K. (1952). The problem of generations. In K. Mannheim (Ed.), Essays on the sociology of knowledge (pp. 276-321). London, UK: Routledge \& Keegan Paul.

Nourkova, V. V. \& Brown, N. R. (2014). Assessing the impact of "the collapse" on the organization and content of autobiographical memory in the former Soviet Union. Unpublished manuscript.

Olick, J. K., \& Robbins, J. (1998). Social memory studies: From "collective memory" to the historical sociology of mnemonic practices. Annual Review Sociology, 24, 105-140. doi:10.1146/annurev. soc.24.1.105
Povrzanović, M. (2000). The imposed and the imagined as encountered by Croatian war ethnographers. Current Anthropology, 41, 151162. doi:10.1086/300125

Rivera, L. A. (2008). Managing "spoiled" national identity: War, tourism, and memory in Croatia. American Sociological Review, 73, 613634. doi:10.1177/000312240807300405

Sahdra, B., \& Ross, M. (2007). Group identification and historical memory. Personality and Social Psychology Bulletin, 33, 384-395. doi: 10.1177/0146167206296103

Schönpflug, U. (2001). Intergenerational transmission of values: The role of transmission belts. Journal of Cross-Cultural Psychology, 32, 174-185. doi:10.1177/0022022101032002005

Schuman, H., \& Scott, J. (1989). Generations and collective memories. American Sociological Review, 54, 359-381. doi:10.2307/2095611

Sperber, D. (1994). The modularity of thought and the epidemiology of representations. In L. A. Hirschfeld \& S. A. Gelman (Eds.), Mapping the mind (pp. 39-67). Cambridge, UK: Cambridge University Press. doi:10.1017/CBO9780511752902.003

Stone, C. B., van der Haegen, A., Luminet, O., \& Hirst, W. (2014). Personally relevant vs. nationally relevant memories: An intergenerational examination of World War II memories across and within Belgian French-speaking families. Journal of Applied Research in Memory and Cognition, 3, 280-286. doi:10.1016/j.jarmac.2014.08. 002

Svob, C. (2014). Intergenerational transmission of historical events via memory (Doctoral thesis, University of Alberta). Retrieved from http:/hdl.handle.net/10402/era.39732

Svob, C., \& Brown, N. R. (2012). Intergenerational transmission of the reminiscence bump and biographical conflict knowledge. Psychological Science, 23, 1404-1409. doi:10.1177/ 0956797612445316

Svob, C., Brown, N. R., Reddon, J. R., Uzer, T., \& Lee, P. J. (2014). The transitional impact scale: Assessing the material and psychological impact of life transitions. Behavior Research Methods, 46, 448-455. doi:10.3758/s13428-013-0378-2

Volkan, V. (1997). Blood lines: From ethnic pride to ethnic terrorism. Boulder, CO: Westview Press.

Weingarten, K. (2004). Witnessing the effects of political violence in families: Mechanisms of intergenerational transmission and clinical interventions. Journal of Marital and Family Therapy, 30, 45-59. doi:10.1111/j.1752-0606.2004.tb01221.x

Welzer, H. (2005). Grandpa wasn't a Nazi: The Holocaust in German family remembrance. New York, NY: American Jewish Committee.

Wohl, M. J., \& Branscombe, N. R. (2009). Group threat, collective angst, and ingroup forgiveness for the war in Iraq. Political Psychology, 30, 193-217. doi:10.1111/j.1467-9221.2008.00688.x

Yehuda, R., Bell, A., Bierer, L. M., \& Schmeidler, J. (2008). Maternal, not paternal, PTSD is related to increased risk for PTSD in offspring of Holocaust survivors. Journal of Psychiatric Research, 42, 1104 1111. doi:10.1016/j.jpsychires.2008.01.002

Zaromb, F., Butler, A. C., Agarwal, P. K., \& Roediger, H. L., III. (2014). Collective memories of three wars in United States history in younger and older adults. Memory \& Cognition, 42, 383-399. doi:10. 3758/s13421-013-0369-7

Zebian, S., \& Brown, N. R. (2014). Living in history in Lebanon: The influence of chronic social upheaval on the organization of autobiographical memories. Memory, 3, 194-211. doi:10.1080/09658211. 2013.775310 